\title{
Clinical Study of Urine Albumin Creatinine Ratio as an Earlier Predictor of Diabetic Nephropathy
}

\author{
Sunil Dhanraj Bhaisare ${ }^{1}$, Anuradha Krishnaraj Rao², Aniruddha Sunildatta Jog ${ }^{3}$, Hariom Uddhav Kolapkar ${ }^{4}$ \\ ${ }^{1}$ Department of General Medicine, Grant Government Medical College and Sir JJ Group of Hospitals, Mumbai, \\ Maharashtra, India. ${ }^{2}$ Department of General Medicine, Grant Government Medical College and Sir JJ Group of \\ Hospitals, Mumbai, Maharashtra, India. ${ }^{3}$ Department of General Medicine, Grant Government Medical \\ College and Sir JJ Group of Hospitals, Mumbai, Maharashtra, India. ${ }^{4}$ Department of General Medicine, Grant \\ Government Medical College and Sir JJ Group of Hospitals, Mumbai, Maharashtra, India.
}

\section{ABSTRACT}

\section{BACKGROUND}

Diabetic nephropathy (DN) is a chronic microvascular complication of diabetes mellitus (DM). Microalbuminuria is an earliest marker of DN. Effective screening measures are required for early diagnosis and management to halt the progression of diabetic nephropathy. We wanted to evaluate urine Albumin Creatinine Ratio (ACR) as an earlier predictor of diabetic nephropathy in comparison to the gold standard test 24-hours urine protein.

\section{METHODS}

This is a cross sectional study conducted among 210 patients of type-2 DM admitted in the medical ward of a tertiary care hospital, who fulfilled the inclusion and exclusion criteria. Relevant history including duration of DM, and other comorbidities was taken from the patients. Vital parameters such as heart rate, systolic and diastolic blood pressure were recorded. CBC, RFT, FBS, PPBS, HbA1c, Fundoscopy were done in all patients. Urine analysis for ACR from random urine sample and 24-hours urine protein from 24-hour urine sample were done.

\section{RESULTS}

Proteinuria was present in $80.95 \%$ of patients and that with 24-hour urinary protein, in $59.04 \%$ patients. ACR showed sensitivity of $100 \%$, specificity of $46.51 \%$ with PPV of $72.94 \%$ and NPV of $100 \%$. ACR has strong positive correlation with 24 hours urinary protein. Positive correlation of urine ACR was seen with serum creatinine, blood urea, $\mathrm{HbA1c}$, anaemia, duration of diabetes and the presence of diabetic retinopathy.

\section{CONCLUSIONS}

ACR shows high sensitivity in the detection of proteinuria, especially microalbuminuria and hence can be considered as an alternative to 24-hour urine protein in an early screening for DN.

\section{KEY WORDS}

Diabetic Nephropathy, Urine ACR, 24 Hour Urine Protein
Corresponding Author: Dr. Anuradha Krishnaraj Rao, Room No. 207, 300 Resident Hostel JJ Hospital Campus, Byculla, Mumbai-400008, Maharashtra, India. E-mail: anurao0011@gmail.com

DOI: $10.14260 /$ jemds/2020/133

Financial or Other Competing Interests: None.

How to Cite This Article:

Bhaisare SD, Rao AK, Jog AS, et al. Clinical study of urine albumin creatinine ratio as an earlier predictor of diabetic nephropathy. J. Evolution Med. Dent. Sci. 2020;9(09):598-602, DOI: 10.14260/jemds/2020/133

Submission 26-12-2019,

Peer Review 03-02-2020,

Acceptance 11-02-2020,

Published 02-03-2020. 


\section{BACKGROUND}

Diabetes Mellitus is an important public health problem. India is home to 69.1 million people with DM and is estimated to have the second highest number of cases of DM in the world after China in 2015.(1) The prevalence of DM in India ranges from $5-17 \%$.(1) Diabetes mellitus causes considerable morbidity and mortality primarily due to micro and macro vascular complications which are preventable(2) One such microvascular complication of diabetes is diabetic nephropathy. Diabetic nephropathy has been didactically categorized into stages based on the values of urinary albumin excretion (UAE). Diabetic nephropathy is a clinical syndrome characterized by persistent albuminuria $(>300$ $\mathrm{mg} / \mathrm{d}$ or $>200 \mathrm{mcg} / \mathrm{min}$ ) that is confirmed on at least 2 occasions 3-6 month apart, a relentless decline in the glomerular filtration rate (GFR) and elevated arterial blood pressure (American Diabetic Association).(3) The total duration of disease was found to be an important risk factor for the development and progression of nephropathy.

Micro-albuminuria is the earliest clinical manifestation of diabetic nephropathy.(4) Its early detection can help the timely use of renal preventive measures. It progresses to overt proteinuria in $20-40 \%$ cases within 10 years period and further progresses to ESRD in $20 \%$ of cases.(5) Thus, microalbuminuria assessment is done for early diagnosis and screening of diabetic nephropathy. Micro-albuminuria may be present even before the diagnosis of DM (especially in Type 2 DM). Therefore, effective screening measures are required for early diagnosis. Even though timed and 24-hour collections of urine are gold standard methods of determining micro-albuminuria, they are slow and cumbersome and are amenable to errors in collection.(6) To avoid this time consuming and cumbersome procedure, random urine sample can be used for quantification of albuminuria. Patient compliance is better with random urine sample collection. Urinary albumin concentration in a random urine sample is variably attributable to circadian rhythm, variation in hydration status, diuresis, exercise and diet.(7) This variation can be eliminated by calculating random urinary albumin: creatinine ratio (RUA: C) in random urine sample. As it is the ratio of two stable rates, it eliminates the effect of time.

Therefore, the present study was planned to study the urine albumin creatinine ratio in patients with diabetic nephropathy.

\section{METHODS}

Prior to the study, ethical clearance was taken from the ethical committee of tertiary care hospital. This crosssectional study was conducted from $1^{\text {st }}$ March 2018 to 1st September 2019. 210 patients of type-2 DM were enrolled in the study. Sample size came out to be 384 based on online sample calculator. As patients with renal failure and diagnosis of hypertension prior to the onset of diabetes mellitus were excluded sample size was taken as 210 .

All patients in medicine wards and OPD in a tertiary care hospital with type 2 diabetes mellitus fulfilling the inclusion criteria were included in the study. Informed and voluntary consent was taken from all the participants in the study.
Patients who have been diagnosed with type 2 diabetes mellitus according to the American Diabetes Association (ADA) and patients who were already taking treatment either OHA or insulin for type 2 DM were included in the study. Patients suffering from type-1 DM, fever, urinary tract infections were excluded. Patients with pre-existing nephropathy, pre-existing hypertension before the diagnosis of DM, bed ridden patients and pregnant women were also excluded in the study. History was taken in the form of questionnaire: Information regarding age, gender, duration of DM, other comorbidities like hypertension, stroke, and complaints of sensory motor neuropathy were recorded. Examination was done in the form of Heart rate, systolic and diastolic blood pressure were measured. Presence of pallor, pedal oedema, crepitations were also recorded. Fundoscopy were done in all patients. Complete blood counts (CBC), Renal function tests (RFT), Fasting blood sugars (FBS) with fasting of 8-10 hours, Post-prandial blood sugars (PPBS) collected 2 hours after food, HbA1c (estimated using HPLC method) were measured in all patients in the study.

For Urine analysis, two samples of urine were collected from the patients, one included random urine sample in a sterile container with a capacity of $10 \mathrm{ml}$ and a urine sterile container of capacity of 5 litre for 24-hours urine sample collection. 24-hour urine sample were used for measurement of 24-hour urine protein. Urine ACR was measured from random urine sample. Urinary albumin was measured by 'Immuno Turbidometry method' while urinary creatinine was measured by 'Jaffe's spectrophotometric method'.

\section{Clinical Definitions (8)}

1. Diabetes mellitus (as per the American Diabetes Association)

- Fasting blood sugar $>/=126 \mathrm{mg} / \mathrm{dl}$ (fasting is defined as no caloric intake for $>=8$ hours)

- 2-hour Post prandial blood sugar >=200 mg/dl during an oral glucose tolerance test. (the test should be performed using a glucose load containing the equivalent of $75 \mathrm{~g}$ anhydrous glucose dissolved in water)

- HbA1c $>=6.5 \%$

- And all those patients who were diagnosed with type 2 diabetes mellitus already on oral hypoglycaemic drugs and/or insulin were also included in the study.

2. Proteinuria is defined as urine Albumin Creatinine Ratio (ACR) in a single spot urine sample

- Normo-albuminuria $=<30 \mathrm{mg} / \mathrm{g}$.

- Micro-albuminuria $=30-299 \mathrm{mg} / \mathrm{g}$.

- Macroalbuminuria $=>300 \mathrm{mg} / \mathrm{g}$.

3. Overt proteinuria is defined as proteinuria of $>150$ $\mathrm{mg} / 24$ hours urine protein.

\section{Statistical Analysis}

Data was collected in a Microsoft Excel database. Statistical analysis was done using nonparametric ANOVA and Fisher test and Pearson correlation. 


\section{RESULTS}

A total of 210 patients participated in the study. The average age of patients in our study was $58.03 \pm 11.23$ years, majority were around the age of 40 to 60 years. The average duration of diabetes in our study population was $7.73 \pm 5.05$ years. Hypertension was the most common comorbid condition in the study accounting for $67 \%$. Other common comorbid conditions were stroke (13.8\%) and IHD (14.76\%). The average heart rate $(87.29 \pm 11.77)$, SBP $(132.65 \pm 22.55)$ and DBP $(82.19 \pm 10.66)$ were within normal limits in our study population. Signs of diabetic retinopathy in the study population which was seen in $52.38 \%$. Majority (36.17\%) of patients had mild NPDR. Others showed presence of cataract (5.71\%) and hypertensive $(7.14 \%)$ changes on fundoscopy. The presence of diabetic retinopathy had a strong positive correlation with that of ACR ( $\mathrm{p}=0.0003$ ).

About $35 \%$ of patients in our study were anaemic defined as haemoglobin less than $10 \mathrm{gm} / \mathrm{dL}$. The presence of anaemia positively correlated with ACR $(\mathrm{p}=0.0003)$ All the renal function parameters were marginally increased in our study population. The average serum creatinine was $1.80 \pm 1.56$ $\mathrm{mg} / \mathrm{dl}$, blood urea was $47.90 \pm 31.76 \mathrm{mg} / \mathrm{dl}$, serum sodium was $143.08 \pm 90.38 \mathrm{meq} / \mathrm{L}$, serum potassium was $4.47 \pm 2.94$ meq/L. The average Fasting blood sugar was 211.88 \pm 75.72 $\mathrm{mg} / \mathrm{dl}$ and Post-prandial blood sugar was $280.78 \pm 90.09$ $\mathrm{mg} / \mathrm{dl}$ in our study population. Proteinuria was found in $79.04 \%$ of patients enrolled in our study on a dipstick method (qualitative). The average urine Albumin: creatinine ratio (ACR) in our patients was $390.95 \pm 1029.8 \mathrm{mg} / \mathrm{g}$. The average 24 -hour urine protein was $631.97 \pm 1387.9 \mathrm{mg}$.

Urine ACR amongst patients in study showed 40 patients with non-proteinuria $(=<30 \mathrm{mg} / \mathrm{g})$, Microalbuminuria $=(30-$ $300 \mathrm{mg} / \mathrm{g}$ ) in 121 patients, and Macroalbuminuria ( $>300$ $\mathrm{mg} / \mathrm{g}$ ) in 49 patients. Maximum patients showed predominance in presence of microalbuminuria.

\begin{tabular}{|c|c|c|}
\hline \multirow{2}{*}{$\begin{array}{c}\text { Micro Albuminuria } \\
\text { by ACR }\end{array}$} & Present & Absent \\
\cline { 2 - 3 } Present & 124 & 46 \\
\hline Absent & 0 & 40 \\
\hline \multicolumn{2}{|c|}{$\begin{array}{l}\text { ACR showed sensitivity of } 100 \% \text {, specificity of } 46.51 \% \text { with PPV of } 72.94 \% \text { and NPV } \\
\text { of } 100 \% .\end{array}$} \\
\hline \multicolumn{2}{|c|}{ Table 1. Comparison of Random Urine ACR with } \\
24-Hour Urine Protein for Proteinuria Assessment \\
\hline
\end{tabular}

As shown in table-1 out of 210 patients enrolled in the study, 40 patients showed absence of proteinuria by either method of screening. 124 patients, demonstrated presence of proteinuria by both the methods. 46 patients, on screening showed the presence of microalbuminuria by urine ACR method, however showed no evidence of proteinuria by the 24-hour method.

\begin{tabular}{|c|c|c|}
\hline Proteinuria & 24 hr Urine Protein & ACR \\
\hline Detected & $124(59.04 \%)$ & $170(80.95 \%)$ \\
\hline Not detected & $86(40.95 \%)$ & $40(19.05 \%)$ \\
\hline p value & \multicolumn{2}{|c|}{$<0.0001$ (Fisher test) } \\
\hline \multicolumn{2}{|c|}{ Table 2. Comparing Presence of Proteinuria by the Two Methods } \\
\hline
\end{tabular}

As shown in table-2, With ACR, proteinuria (microalbuminuria/macroalbuminuria) was present in $80.95 \%$ patients. With $24 \mathrm{hr}$ urinary protein, proteinuria was present in $59.04 \%$ patients $(\mathrm{p}<0.0001)$.

\begin{tabular}{|c|c|c|c|c|}
\hline & Urine Albumin Creatinine Ratio (mg/g) & p Value* \\
\hline Parameter & $<\mathbf{3 0}$ & $\mathbf{3 0 - 3 0 0}$ & $>\mathbf{3 0 0}$ & N $^{*}$ \\
\hline $\begin{array}{c}\text { Duration of diabetes } \\
\text { (years) }\end{array}$ & $6.02 \pm 3.43$ & $7.02 \pm 4.66$ & $10.89 \pm 5.86$ & $<0.0001$ \\
\hline $\begin{array}{c}\text { 24-hr urine protein } \\
\text { (mg) }\end{array}$ & $2.18 \pm 9.66$ & $284.90 \pm 308.45$ & $2035.93 \pm 2356.1$ & $<0.0001$ \\
\hline $\begin{array}{c}\text { Fasting Blood Sugar } \\
\text { (mg/dl) }\end{array}$ & $200.77 \pm 53.32$ & $217.15 \pm 82.19$ & $211.33 \pm 79.42$ & 0.76 \\
\hline Table 3. Comparing ACR Parameters with Other Parameters in Study \\
\hline *Non parametric ANOVA
\end{tabular}

As shown in table-3 there was significant difference seen in the duration of diabetes in patients with micro, macro and normo-albuminuria, with duration of diabetes highest in patients with macro-albuminuria. ACR also showed positive correlation with that of duration of DM ( $p<0.0001)$. 24hr urinary protein was significantly high in patients with macroalbuminuria, showing a positive correlation ( $p$ $<0.0001$ ) No significant difference was seen in FBS among patients with micro, macro and normo-albuminuria. HbA1c showed positive correlation with ACR ( $p<0.0001)$. Amongst 210 patients enrolled in our study, USG KUB were performed in 166 patients. Normal study was seen in $73.49 \%$ patients. 44 patients showed presence of medical renal disease with or without $(3)$ maintained cortico-medullary differentiation, and these patients also showed positive correlation with ACR ( $p$ $<0.0001)$. In our study, patients were also screened for macrovascular complications like ischemic heart disease/ dilated cardiomyopathy. Based on 2D-Echo findings, almost $31 \%$ patients showed features of IHD/ DCMP. However, ACR did not show any positive correlation with the same $(p=0.07)$.

Table-4 shows correlation of ACR with various parameters in the study. ACR thus shows strong positive correlation with 24-hr urinary protein. Positive correlation was seen with serum creatinine, blood urea, serum potassium. Positively correlation of ACR was seen with HbA1c, anaemia, duration of diabetes and the presence of diabetic retinopathy. ACR was negatively correlated to Hemiparesis/Stroke/IHD (i.e. macrovascular complications of DM)

\begin{tabular}{|c|c|c|}
\hline & Correlation Coefficient & p Value \\
\hline 24-hour urine protein & 0.87 & $<0.0001$ \\
\hline Serum Creatinine & 0.45 & $<0.0001$ \\
\hline Serum Urea & 0.37 & $<0.0001$ \\
\hline Serum Sodium & -0.04 & 0.54 \\
\hline Serum potassium & 0.10 & 0.13 \\
\hline Medical Renal disease on USG & 0.39 & $<0.0001$ \\
\hline HbA1c & 0.36 & $<0.0001$ \\
\hline Diabetic retinopathy & 0.24 & 0.0003 \\
\hline Duration of diabetes & 0.40 & $<0.0001$ \\
\hline Hemiparesis / Stroke & -0.09 & 0.18 \\
\hline 2D Echo (IHD/DCMP) & 0.12 & 0.07 \\
\hline Anaemia (Hb $<10)$ & 0.26 & 0.0003 \\
\hline Systolic BP & 0.07 & 0.30 \\
\hline Diastolic BP & 0.07 & 0.26 \\
\hline Table 4. Correlation of ACR with Various Parameters \\
\hline \multicolumn{2}{|l}{} \\
\hline
\end{tabular}

\section{DISCUSSION}

Diabetic nephropathy (DN) is the long standing micro vascular complication of diabetes mellitus. In this study 210 patients diagnosed with type-2 DM were enrolled and analysed. The average age of patients in our study was $58.03 \pm 11.23$ years with majority of patients in the age group of 40 to 80 years and the average duration of diabetes mellitus was $7.73 \pm 5.05$ years with majority of patients 
develop DN within 10 years of onset of diabetes. Since the average age of diabetes in India is 40 years (39.6 years),(9) the average age of diabetic nephropathy in our study corresponds to average duration of onset after diabetes. The result of our study was in accordance to study conducted by Vargashee A et al.(10) and study by Chowta NK.(11) Rossing $\mathrm{P}(12)$ reported the peak incidence of nephropathy as 10 to 20 years after diabetes onset and then it occurs as a progressive decrease. The relatively less duration of diabetes in our study may be because of excluding the patients who were already diagnosed as nephropathy due to any cause.

In our study hypertension was the most common (67.14\%) co-morbid condition. Hypertension is considered as the most common companion of diabetes, with the study reporting hypertension is approximately twice as prevalent in patients with diabetes compared to the general population.(13) Similar to our study the incidence of hypertension in patients with DN was $66.3 \%$ in study conducted by Anand Verma(14) and $60.5 \%$ by Molefe-Baikai 0J.(15) Despite the presence of $67.14 \%$ of patients with hypertension, the average systolic and diastolic blood pressure were within the normal limits of the study population. (SBP values ranged between a maximum of 210 to a minimum of 90 whereas the DBP ranged between a maximum of 140 to a minimum of 60 ) Also, the patients who were diagnosed with hypertension prior to that of DM were excluded from the study. Thus, no strong correlation was found amongst the blood pressure and ACR values in the study.

Signs of diabetic retinopathy (DR) was seen in $52.38 \%$ of enrolled patients in our study, with majority $(36.17 \%)$ reporting mild non-proliferative diabetic retinopathy which was similar to the incidence of diabetic retinopathy in study conducted by Xiao-Qian Li(16) and Parving HH.(17) Trevisan et al(18) and Junlin Zhang(19) indicated that the severity of glomerular lesions was significantly associated with DR and it was an independent risk factor for the renal outcomes in patients with DN.

The average albumin: creatinine ratio and 24-hour urine protein in our patients was $390.95 \pm 1029.8 \mathrm{mg} / \mathrm{g}$ and 631.97 $\pm 1387.9 \mathrm{mg}$ respectively. With ACR, proteinuria was present in $80.95 \%$ patients and with $24 \mathrm{hr}$ urinary protein, proteinuria was present in $59.04 \%$ patients $(\mathrm{p}<0.0001)$. Thus, ACR showed sensitivity of $100 \%$, specificity of $46.51 \%$ with PPV of $72.94 \%$ and NPV of $100 \%$. The above results can be compared to study conducted by Ewald and Attia(20) found that ACR on a random specimen had a sensitivity of $90 \%$ and a specificity of $84 \%$, and they suggested that ACR on a random urine specimen be used routinely as the initial test in screening diabetics for MA. The result of our study and similar other studies have reported higher sensitivity of ACR in diagnosing micro-albuminuria. And thus, should be used routinely for early diagnosis of $\mathrm{DN}$, since it is easy to conduct and with a very high sensitivity.

Majority of the patients had ACR between 30-300 mg/g i.e. microalbuminuria followed by those with $>300 \mathrm{mg} / \mathrm{g}$ i.e. macroalbuminuria. Among those with ACR $>300 \mathrm{mg} / \mathrm{g}$ (macroalbuminuria/overt proteinuria) the duration of diabetes and $24 \mathrm{hr}$ urinary protein was significantly higher as compared to those with ACR $30-300 \quad \mathrm{mg} / \mathrm{g}$ (microalbuminuria). The above results were in line with study conducted by Monika Pathania where the average duration of diabetes was significantly high in patients with macro albuminuria/overt proteinuria as compared to those with microalbuminuria. Similarly, $24 \mathrm{hr}$ urinary protein was also significantly high in patients with macroalbuminuria.

USG -KUB was performed in 166 patients out of the 210 and was found to be normal in $73.49 \%$ patients. Among those with abnormal findings, medical renal disease with maintained corticomedullary differentiation (CMD) was common finding. The USG findings were positively correlated with ACR in our study. The presence of normal CMD in majority of the patients with abnormal USG denotes that majority are still in the early phase DN. Only in advanced stage of nephropathy cortical echotexture and CMD are altered. Our results were similar to study conducted by Basanta Majari(21) in patients with DN, who reported $89 \%$ patients had normal CMD.

Patients in our study were also evaluated for macrovascular complications of diabetes such as IHD/DCMP, Stroke. 2-D echo were performed in patients and were suggestive of features of IHD/DCMP in about 31\% patients. However, no positive correlation with urine ACR were found suggesting that ACR does not correlate well with the macrovascular complications of DM.

We also tried analysing correlation of ACR with the various parameters in the study. We found that urine ACR has a strong positive correlation with $24 \mathrm{hr}$ urinary protein. Also, positive correlation was seen with serum creatinine, blood urea, potassium. It was also positively correlated with HbA1c, anemia, duration of diabetes, presence of diabetic retinopathy. Similar findings were reported by Yadav BK,(22) Biradar SB(23) and Tarig Karar.(24) Thus the result of our study and similar other study suggest that random urinary ACR is appropriate for quantitative assessment of microalbuminuria and can be used instead of using 24-hours urine protein.

\section{CONCLUSIONS}

ACR has a strong positive correlation with 24-hr urinary protein. Urinary ACR had high sensitivity in diagnosing micro-albuminuria. As it is easy to perform, it should be included in routine practice for early screening of nephropathy in all patients of type-2 DM. Positive correlation of ACR was seen with $\mathrm{HbA1c}$, anaemia, and duration of diabetes indicating the role of strict glycaemic control, and early detection of proteinuria. Positive correlation of ACR was seen with diabetic retinopathy.

\section{ACKNOWLEDGEMENT}

We thank Dr. Vidya Nagar, Head of Department, Department of General Medicine, Grant Government Medical College and Sir JJ Group of Hospitals for her encouragement and support. 


\section{REFERENCES}

[1] Tripathy JP, Thakur JS, Jeet G, et al. Prevalence and risk factors of diabetes in a large community-based study in North India: results from a STEPS survey in Punjab, India. Diabetol Metab Syndr 2017;9:8.

[2] Viswanathan V. Prevention of diabetic nephropathy: A diabetologist's perspective. Indian Society of Nephrology 2004;14:157-62.

[3] American Diabetes Association. Standards of medical care in diabetes. Diabetes Care 2005;28(Suppl 1):S4-S36.

[4] Valizadeh M, Farahmand NA, Nasab MN, et al. Determining the value of albumin to creatinine ratio in a single morning sample, compared to the 24-hour urinary albumin excretion test, for determining microalbuminuria in diabetic patients. Iranian Journal of Diabetes and Lipid Disorders 2009: p. 27-36.

[5] Pathania M, Rathaur VK, Yadav N, et al. Quantitative micro-albuminuria assessment from 'random voided urinary albumin: creatinine ratio' versus ' 24 hours urinary albumin concentration' for screening of diabetic nephropathy. J Clin Diagn Res 2013;7(12):2828-31.

[6] Gyamlani GG, Bergstralh EJ, Slezak JM, et al. Urinary albumin to osmolality ratio predicts 24-hour urine albumin excretion in diabetes mellitus. Am J kidney Dis 2003;42(4):685-92.

[7] Price CP, Newall RG, Boyd JC. Use of protein: creatinine ratio measurements on random urine samples for prediction of significant proteinuria: a systematic review. Clin Chem 2005;51(9):1577-86.

[8] Jameson JL, Fauci AS, Kasper DL, et al. Harrison's Principles of Internal Medicine. $20^{\text {th }}$ edn. New York: Vol. 2. McGraw-Hill 2012: p. 2178-95, 2896-928.

[9] India State-Level Disease Burden Initiative Diabetes Collaborators. The increasing burden of diabetes and variations among the states of India: the Global Burden of Disease Study 1990-2016. Lancet Glob Health 2018;6(12):e1352-62.

[10] Varghese A, Deepa R, Rema M, et al. Prevalence of microalbuminuria in type 2 diabetes mellitus at a diabetes centre in southern India. Postgrad Med J 2001;77(908):399-402.

[11] Chowta NK, Pant P, Chowta MN. Microalbuminuria in diabetes mellitus: association with age, sex, weight and creatinine clearance. Indian Journal of Nephrology 2009;19(2):53-6.
[12] Rossing P, Hougaard P, Parving HH. Progression of microalbuminuria in type 1 diabetes: ten-year prospective observational study. Kidney Int 2005;68(4):1446-50.

[13] Epstein M, Sowers JR. Diabetes mellitus and hypertension. Hypertension 1992;19(5):403-18.

[14] Verma A, Vyas S, Agarwal A, et al. Diabetic Kidney Disease and Hypertension: a true love story. Journal of Clinical and Diagnostic Research 2016;10(3):0C11OC13.

[15] Molefe-Baikai OJ, Molefi M, Cainelli F, et al. The prevalence of microalbuminuria and associated factors among patients with type 2 diabetes mellitus in Botswana. Niger J Clin Pract 2018;21(11):1430-7.

[16] Li XQ, Zheng X, Chen M, et al. Characteristics of diabetic nephropathy patients without diabetic retinopathy: a retrospective observational study. Medicine (Baltimore) 2017;96(18):e6805.

[17] Parving HH, Gall MA, Skøtt P, et al. Prevalence and causes of albuminuria in non-insulin-dependent diabetic patients. Kidney Int 1992;41(4):758-62.

[18] Trevisan R, Vedovato M, Mazzon C, et al. Concomitance of diabetic retinopathy and proteinuria accelerates the rate of decline of kidney function in type 2 diabetic patients. Diabetes Care 2002;25(11):2026-31.

[19] Zhang J, Wang Y, Li L, Diabetic retinopathy may predict the renal outcomes of patients with diabetic nephropathy. Ren Fail 2018;40(1):243-51.

[20] Ewald B, Attia J. Which test to detect microalbuminuria in diabetic patients? A systematic review. Aust Family Phys 2004;33(7):565-71.

[21] Manjari BS, Debata M. Role of intrarenal resistivity index by duplex ultrasonography in diabetic nephropathy and its clinico biochemical correlation. Yuva Journal of Medical Science 2018;4(1):01-11.

[22] Yadav BK, Adhikari S, Gyawali P, et al. Use of protein: creatinine ratio in a random spot urine sample for predicting significant proteinuria in diabetes mellitus. Nepal Med Coll J 2010;12(2):100-5.

[23] Biradar SB, Kallaganad GS, Rangappa M, et al. Correlation of spot urine protein-creatinine ratio with 24-hour urinary protein in type 2 diabetes mellitus patients: a cross sectional study. J Res Med Sci 2011;16(5):634-9.

[24] Karar T, Alniwaider RAR, Fattah MA, et al. Assessment of microalbuminuria and albumin creatinine ratio in patients with type 2 diabetes mellitus. J Nat Sci Biol Med 2015;6(Suppl

1):S89-S92. 